\title{
THE PATTERN OF USE OF MOUTHGUARDS IN RUGBY LEAGUE (A STUDY OF THE 1986 AUSTRALIAN RUGBY LEAGUE TOURING TEAM)
}

\author{
P. J. CHAPMAN \\ University of Queensland Dental School, Brisbane, Australia
}

\section{ABSTRACT}

Generally speaking, in contact sports the higher the grade of competition the greater the risk of a player sustaining any type of injury. Therefore it is important to conduct studies periodically of international sporting teams from different countries to detect any changes in regional injury patterns, besides assessing attitudes to the use of available protective equipment. A study of the prevalence of orofacial injuries and use of mouthguards by members of the 1984 Great Britain Rugby League Touring Team has previously been reported (Chapman, 1985a). In order to obtain a suitable basis for comparison of those results, a similar study of the members of the 1986 Australian Rugby League Touring Team to Great Britain was conducted. The most important finding was the much higher usage rate of mouthguards by the Australian footballers when compared with the British figure. Results of the study also support the function of mouthguards in reducing the incidence of orofacial injuries in contact sports.

Key words: Mouthguards, Orofacial injuries, International level, Rugby League

\section{INTRODUCTION}

An important preventive aspect of sports medicine is to encourage the use of mouthguards in contact sports. A standard maxillary mouthguard provides the following protection (Chandler et al, 1987; Chapman, 1987; Upson, 1982).

(i) Significant reduction in the risk of concussion injury following an impact striking the mandible from below which causes traumatic closure of the mandible. The force distribution pattern subsequent to such an impact is shown in Fig. 1. If the impact is of sufficient intensity to cause sudden head movement, this will cause rotational acceleration of the head with concomitant effects in the brain which may cause concussion. The mouthguard acts by reducing the force transferred across both the occlusal plane and the mandibular joints. This latter phenomena is due to the fact that the closed condylar position is about $2 \mathrm{~mm}$ forwards of normal. By contrast, impacts striking the mandible from in front will cause sudden backward movement of the head with linear acceleration. Of these two basic types of acceleration, rotational acceleration is far more likely to cause cerebral dysfunction and unconsciousness.

(ii) Significant reduction in the incidence of injuries of the maxillary teeth subsequent to either a frontal impact, or an impact striking the mandible from below, causing traumatic closure of the mandible to occur. There is also some protection of the mandibular teeth if traumatic closure of the mandible occurs.

(iii) Significant reduction in the incidence of intraoral and perioral lacerations.

(iv) Provides limited protection against the possibility of sustaining a fracture of the mandible following traumatic closure.

Except for frontal protection of the anterior maxillary teeth these safety features are all improved with use of a bimaxillary mouthguard (Chapman, 1986b). Additionally the bimaxillary mouthguard provides protection against

Address for correspondence:

P. J. Chapman, MB, BS, MDSc, FASMF

University of Queensland Dental School

Turbot Street

Brisbane

Queensland 4000

Australia

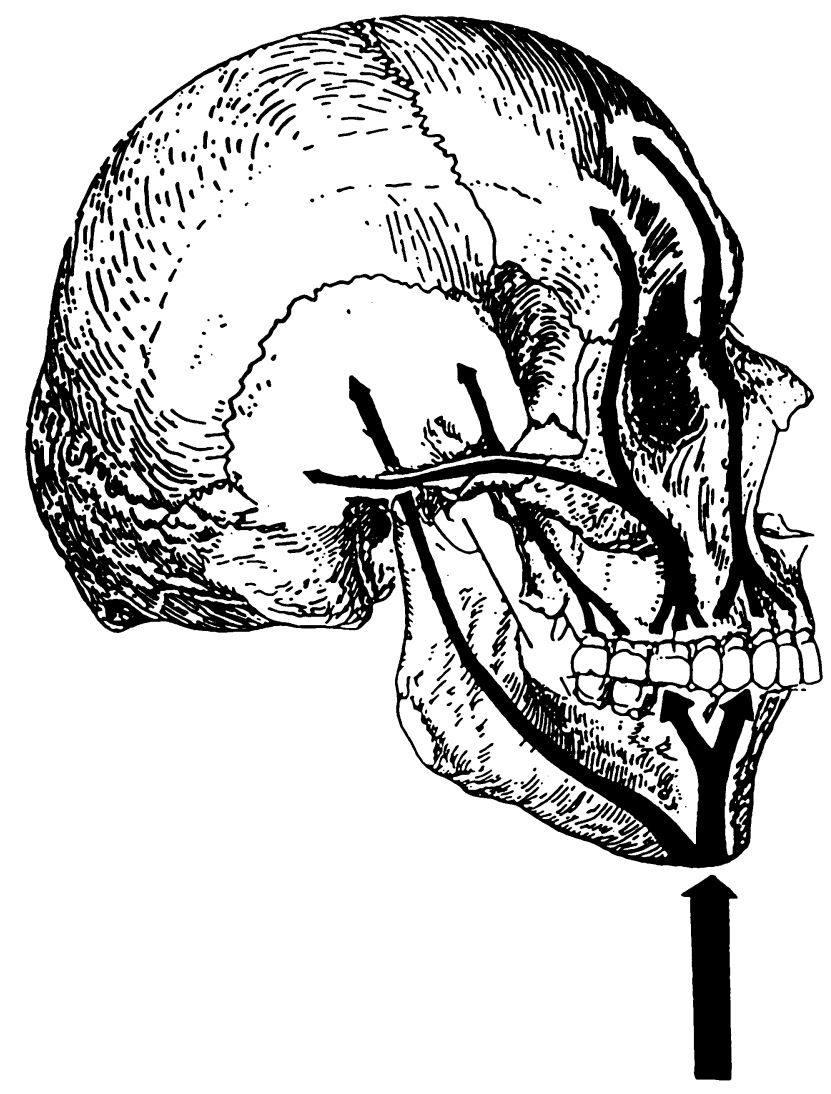

Fig. 1: This shows the pattern of force distribution following an impact striking the mandible from below. The resultant acceleration of the head would be of the rotational type. If, by comparison, the impact struck the chin point from in front, then most or all of the force would travel directly backwards through the mandible, resulting in linear acceleration of the head.

fracture of the mandible following impacts from any direction, as the mandible is now stabilised to the skull. Also the anterior mandibular teeth are now protected against frontal impacts (Chapman, 1986b; Chapman, 1986c).

Previous extensive studies of the Rugby Codes of football (Rugby Union and Rugby League) in Australia involving 216 footballers, extending from club grades (4 levels) to international grade of competition, showed that the overall usage rate of mouthguards was very high at approximately 75\%, (Chapman, 1985b; Chapman, 1985c). The overall average playing period for each footballer was $\mathbf{1 1 . 5}$ years and of the $\mathbf{2 7 . 3 \%}$ who had previously sustained an orofacial injury (includes dental and dentoalveolar 
injuries; intraoral and perioral lacerations; and fractures of the jaws) $69.5 \%$ were not wearing a mouthguard at the time. Many of the footballers who wore self-fitted mouthguards reported difficulties with breathing, speaking and gagging. By contrast very few difficulties were experienced by those who wore professionally-fitted mouthguards. The studies also showed that the most ardent users of mouthguards were usually those who had commenced wearing a mouthguard at an early age or alternatively had suffered a significant orofacial injury when not wearing a mouthguard.

A study of the prevalence of orofacial injuries and use of mouthguards by the 28 members of the 1986 Australian Rugby League Touring Team to Great Britain (The Kangaroos) was undertaken to provide further information and knowledge of this area and allow comparisons with the results of the previous study of the 1984 Great Britain Rugby League Touring Team to Australia (Chapman, 1985a).

The 1986 Kangaroos had an unbeaten record during their tour of Great Britain and were considered one of the greatest teams of all times. Fig. 2 shows the Australian forward Greg Dowling being driven backwards in a tackle by two Great Britain forwards in the Third Test. This demonstrates the physical nature of the game.

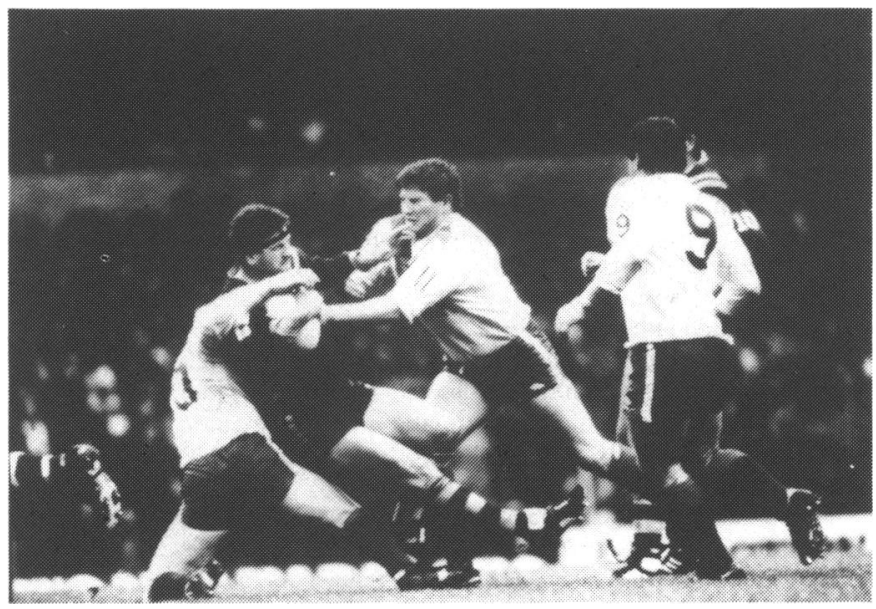

Fig. 2: This picture illustrates the definition of a contact sport. Greg Dowling, an Australian prop forward, is driven backwards in a strong tackle by two British forwards in the Third Test.

Rugby football originated at Rugby School in England in 1823 when William Webb Ellis, playing in a soccer match, picked up the ball and ran with it instead of kicking it. The concept of running and passing the ball soon became popular and formal rules were devised for the game, which the founders called Rugby Union. Rugby League football formed as a breakaway code from Rugby Union in England in 1895 and some of the rules were altered although the games still remained similar. The reason for the separation was that the rules of Rugby Union did not allow clubs to provide injury insurance cover for the players. The first matches were played in Australia in 1907.

Besides Great Britain and Australia, Rugby League is played in New Zealand, France and Papua New Guinea, with regular Test Matches being played between these nations.

\section{METHODOLOGY AND RESULTS}

A questionnaire study was completed by 28 players of the 1986 Australian Team. This questionnaire format had been devised by the author and used in previous retrospective studies. The questions and the respective results are shown in Table 1 together with the results of the previous study of the 1984 British Team.

TABLE I

Results of questionnaire survey of the 1986 Australian Rugby League Touring Team

\begin{tabular}{|c|c|c|}
\hline \multirow[t]{2}{*}{ Question } & \multicolumn{2}{|c|}{ Response } \\
\hline & $\begin{array}{l}\text { Australian } \\
\text { Team }\end{array}$ & $\begin{array}{l}\text { British* } \\
\text { Team }\end{array}$ \\
\hline Overall number & 28 & 28 \\
\hline Overall average age & 24.3 yrs & 24.1 yrs \\
\hline $\begin{array}{l}\text { Overall number who believed in effectiveness } \\
\text { of mouthguards }\end{array}$ & all & all \\
\hline Number currently wearing a mouthguard & $26(92.8 \%)^{* *}$ & $7(25 \%)$ \\
\hline $\begin{array}{l}\text { Regarding mouthguard wearers: } \\
\text { overall average age when started regular } \\
\text { participation in rugby football }\end{array}$ & 7.1 yrs & 10.5 yrs \\
\hline $\begin{array}{l}\text { average age when started wearing a } \\
\text { mouthguard }\end{array}$ & $14.9 \mathrm{yrs}$ & 20.2 yrs \\
\hline $\begin{array}{l}\text { average delay before commenced wearing } \\
\text { a mouthguard }\end{array}$ & 6.2 yrs & 9.7 yrs \\
\hline $\begin{array}{l}\text { number who believe wearing mouthguards } \\
\text { should be made compulsory }\end{array}$ & $18(69.2 \%)$ & $2(28.6 \%)$ \\
\hline $\begin{array}{l}\text { number who would not play without their } \\
\text { mouthguard }\end{array}$ & $14(53.8 \%)$ & $1(14.3 \%)$ \\
\hline $\begin{array}{l}\text { number who would be very reluctant to } \\
\text { play without their mouthguard }\end{array}$ & $10(38.5 \%)$ & $3(42.9 \%)$ \\
\hline $\begin{array}{l}\text { number prepared to play without their } \\
\text { mouthguard }\end{array}$ & $2(7.7 \%)$ & $3(42.9 \%)$ \\
\hline $\begin{array}{l}\text { Number of non-wearers previously advised } \\
\text { to wear a mouthguard }\end{array}$ & $2(100 \%)$ & $9(42.9 \%)$ \\
\hline $\begin{array}{l}\text { Number of non-wearers who had previously } \\
\text { worn a mouthguard }\end{array}$ & $2(100 \%)$ & $6(28.6 \%)$ \\
\hline $\begin{array}{l}\text { Number who had previously sustained an } \\
\text { orofacial injury requiring treatment } †\end{array}$ & $10(35.7 \%)$ & $17(60.7 \%)$ \\
\hline $\begin{array}{l}\text { Regarding those who had sustained an } \\
\text { orofacial injurytt: }\end{array}$ & & \\
\hline type of injury & & \\
\hline — dental/dentoalveolar & 6 & 14 \\
\hline - intraoral or perioral laceration & 6 & 8 \\
\hline - fracture of the mandible & 1 & 0 \\
\hline $\begin{array}{l}\text { number who were wearing a mouthguard } \\
\text { at the time of injury }\end{array}$ & $2(20 \%)$ & $1(5.9 \%)$ \\
\hline $\begin{array}{l}\text { number of non-wearers who then started } \\
\text { wearing a mouthguad }\end{array}$ & $7(87.5 \%)$ & $4(25 \%)$ \\
\hline
\end{tabular}

Explanatory notes

* Chapman, 1985a

** all were standard professionally-fitted mouthguards except for two: a bimaxillary mouthguard and a self-fitted mouthguard.

† orofacial injuries include dental and dentoalveolar injuries; intraoral and perioral lacerations; and fractures of the jaws. It does not include nasal or zygomatic bone fractures.

t† some players had been injured on more than one occasion.

\section{DISCUSSION}

It is interesting to compare certain differences between the two international teams according to the results in Table I. It should be understood when interpreting mouthguard usage rates that similar conditions apply in both countries regarding provision of mouthguards. That is, mouthguards are generally not provided free of cost by government health services or the football club to which a player is contracted and must therefore be purchased by the individual although there are exemptions e.g. in Great 
Britain, all St. Helens Rugby League players are provided with mouthguards free of charge. Also the use of mouthguards is not compulsory in the rules of either Rugby League or Rugby Union. However, under the new freedom of contract for players in Great Britain some clubs are enforcing the use of mouthguards otherwise holding the player responsible for fees incurred as a result of dental injuries.

All members of both teams believed that mouthguards provide significant protection for the player, a finding which is compatible with the usage rate of the Australian Team but not with that of the British Team. 92.8\% of the Australian Team currently wore a mouthguard, the two non-wearers having each lost their mouthguard over the two years previously but neither had yet obtained a replacement. By contrast only $25 \%$ of the British Team wore mouthguards (Chapman, 1985a). Also, on average, the mouthguard wearers in the Australian Team commenced wearing mouthguards 3.5 years sooner after starting regular participation in the sport, compared with the British mouthguard wearers (Chapman, 1985a). Additionally, $69.2 \%$ of mouthguard wearers in the Australian Team felt mouthguards should be made compulsory equipment for the game above a certain level compared with only $28.6 \%$ in the British Team (Chapman, 1985a). Also, only $7.7 \%$ of the mouthguard wearers in the Australian Team were prepared to play a game without their mouthguard, compared with $42.9 \%$ of the British Team (Chapman, 1985a).

In the Australian Team $35.7 \%$ had previously sustained an orofacial injury which required treatment, compared with $60.7 \%$ in the British Team, a ratio of $1: 1.7$ respectively (Chapman, 1985a). Of the injured Australian Team members $20 \%$ were wearing a mouthguard at the time of the injury compared with $5.9 \%$ of the injured British Team members (Chapman, 1985a). The attitudinal differences between the two teams is further shown by the fact that $87.5 \%$ of the injured Australian Team members who were not wearing a mouthguard then commenced wearing a mouthguard, compared with only $25 \%$ of the injured British Team members (Chapman, 1985a).

The protective function of mouthguards can be gauged if the injured in both teams are combined in a single group.
This shows that $89.9 \%$ of those who had sustained an orofacial injury were not wearing a mouthguard at the time.

\section{CONCLUSION}

Results of an orofacial injury study of the 1986 Australian Rugby League Touring Team has been presented. The important differences to the results of a similar study of the 1984 Great Britain Rugby League Touring Team have been discussed, the most vivid difference being in the percentage who wore mouthguards, $92.8 \%$ and $25 \%$, for the Australian and British teams respectively. This would have attributed to an orofacial injury incidence rate in the British Team of almost double that of the Australian Team. The study reinforces the importance of mouthguards in contact sports in reducing the risk of orofacial injuries.

\section{ACKNOWLEDGEMENT}

The author acknowledges the willing co-operation of the members of the 1986 Australian Team when conducting the survey.

\section{References}

Chandler, N. P., Wilson, N. H. F. and Daber, B. S., 1987 "A modified maxillary mouthguard". Brit.J.Sports Med. 21: 27-28.

Chapman, P. J., 1985a "Orofacial injuries and attitudes to the use of mouthguards by the 1984 Great Britain Rugby League Touring Team". Brit.J.Sports Med. 19: 34-36.

Chapman, P. J., 1985b "The prevalence of orofacial injuries and use of mouthguards in Rugby Union". Aust.Dent.J. 30: 364-367.

Chapman, P. J., 1985c "The prevalence of orofacial injuries and use of mouthguards in Rugby League". Aust.J.Sci.Med.Sport 17 (3): 15-18.

Chapman, P. J., 1986a "Prevention of orofacial sporting injuries in children and young adolescents". Aust.J.Sci.Med.Sport 18 (2): 3-6.

Chapman, P. J., 1986b "The bimaxillary mouthguard: a preliminary report of use in contact sports". Aust.Dent.J. 31: 200-206.

Chapman, P. J., Corner, J. P. and Whitney, C. W., 1986c "Comparison of impact attenuation properties of the bimaxillary mouthguard and a standard (maxillary) mouthguard: a cadaver study involving a graduated series of impacts to the mandible with simultaneous monitoring of head acceleration, intracranial pressure and mandibular strain". In: Abstracts of the 23rd World Congress of Sports Medicine (FIMS). University of Queensland Press. Brisbane. 31.

Chapman, P. J 1987 "Concussion in contact sports and importance of mouthguards in protection". In Krakauer, L. J. (Ed.): The 1986 Year Book of Sports Medicine. Year Book Medical Publishers Inc. Chicago. 232-234.

Upson, N., 1982 "Dental injuries and the attitudes of Rugby players to mouthguards". Brit.J.Sports Med. 16: 241-244.

Title:

BOOK REVIEW

Editors:

\title{
DIAGNOSTIC PICTURE TESTS IN ORTHOPAEDICS
}

Publishers:

\author{
L. Kessel and U. Boundy
}

Wolfe Medical Publications Ltd. 1987

Price: $\mathbf{f 6 . 5 0} 128$ pages 191 figures Soft cover ISBN 0723409005

This book is a form of not-so-trivial pursuits. Clinical photographs or X-rays are printed and you are requested to make a spot diagnosis. The photographs taken by the senior photographer at The Royal National Orthopaedic Hospital, Ms. Uta Boundy, are all very good. There are 191 conditions and the quiz is the sharp brain child of the late Professor Lipmann Kessel. A score of 185 or more correct is excellent, 160 or more good, 140 fair and below 100 - poor (but only if you are practising orthopaedics). 